\title{
CARGA DE TRABALHO FÍSICO E POSTURA NA COLETA DE PINHÃO NA REGIÃO SERRANA DE SANTA CATARINA
}

\author{
Pedro Caldas de Britto ${ }^{1}$; Eduardo da Silva Lopes ${ }^{2 *}$; Felipe Martins de Oliveira $^{1}$; Carla Krulikowski Rodrigues ${ }^{1}$; \\ João Fert Neto ${ }^{3}$; Maurício Cesar de Souza ${ }^{3}$ \\ ${ }^{1}$ Universidade Estadual do Centro-Oeste, Programa de Pós-Graduação em Ciências Florestais, Irati, Paraná, Brasil - pcdbritto@ hotmail.com; \\ eng.oliveirafm@gmail.com; carlakr@gmail.com \\ 2* Universidade Estadual do Centro-Oeste, Departamento de Engenharia Florestal, Irati, Paraná, Brasil - eslopes@cnpq.br \\ ${ }^{3}$ Universidade do Estado de Santa Catarina, Departamento de Engenharia Florestal, Lages, Santa Catarina, Brasil - joao.fert@udesc.br; \\ msouza@cbm.sc
}

Recebido para publicação: 30/08/2017 - Aceito para publicação: 18/10/2017

\begin{abstract}
Resumo
A coleta do pinhão ou sementes de Araucaria angustifolia, representa uma importante fonte de renda para as famílias de propriedades rurais no Sul do Brasil. A derrubada de pinhas é uma técnica empregada posteriormente ao período de defeso do pinhão conforme determinado pela Normativa DC/Ibama n.20/76. Na derrubada, emprega-se a escalada de árvores pelos trabalhadores rurais, com auxílio de equipamentos. Neste contexto, objetivou-se analisar a carga de trabalho físico e as posturas adotadas pelos trabalhadores na coleta do pinhão, visando obter melhoria nas condições de trabalho, conforto, saúde e segurança. $\mathrm{O}$ estudo foi realizado em propriedades rurais da região Serrana de Santa Catarina, Brasil. A carga de trabalho físico foi obtida por meio do levantamento da frequência cardíaca dos trabalhadores durante a execução do trabalho, por meio de um monitor Polar Ou, e o trabalho foi classificado segundo metodologia proposta por Apud (1989). A avaliação das posturas foi feita por meio de filmagens dos trabalhadores e os dados foram submetidos para análise no software "WinOwas" de análises de posturas. Os resultados mostraram que a subida e descida das árvores foram as fases do trabalho de maior exigência física e causadora de maior apreensão nos trabalhadores, devido ao elevado risco de acidentes, sendo o trabalho classificado como de exigência física moderadamente pesada. Já as posturas se mostraram inadequadas nas fases de derrubada e catação das pinhas, sendo recomendada a adoção de medidas ergonômicas para a melhoria das condições de trabalho.
\end{abstract}

Palavras chave: Ergonomia florestal, fisiologia, saúde, sobrecarga física.

\begin{abstract}
Physical workload and posture on pine nut collection in Santa Catarina. The collection of pine nut, or seeds of Araucaria angustifolia, represents an important income source for farm families in Southern Brazilian regions. Pinning is a technique used after the pinion closure period as determined by the DC/Ibama n.20/76 regulation. On the pinning process, rural workers climb trees by using auxiliary equipment. In this context, this research aimed to analyze the physical workload and posture adopted by workers in pine nut collection to improve the comfort conditions, health and safety. The data were collected on farms in the mountainous region of Santa Catarina State, Brazil. The physical workload was obtained by monitoring heart rate of workers at work by using the monitor Polar Oy, and the work was classified according to the methodology proposed by Apud (1989). The assessment of posture was taken by filming the workers, and the data were submitted for analysis in the analysis of postures "WinOwas" software. The results showed that the clibbing and clib down of the trees were the work phases more physically demanding and that caused greater strain on workers due to the high risk of accidents. The work is classified as moderately heavy physical demand. The approach proved inadequate in the stages of overthrow and grooming of the cones. The adoption of ergonomic measures to improve working conditions is recommended.

Keywords: Forest ergonomics, physiology, health, physical overload.
\end{abstract}

\section{INTRODUÇÃO}

A Floresta Ombrófila Mista, também denominada de Mata das Araucárias, é considerada integrante do Bioma Mata Atlântica, conforme a Lei N 11.428 de 22 de dezembro de 2006 (BRASIL, 2006). Ela apresenta grande importância em termos ecológico-econômico, devido a sua característica única de abrigar a espécie de conífera mais expressiva da vegetação brasileira, a Araucaria angustifolia (Bert.) O. Kuntze. (LORENZI, 2008). A araucária é uma planta dioica, com tronco retilíneo, de 90 a $180 \mathrm{~cm}$ de diâmetro (LORENZI, 2008). Os seus pseudofrutos ficam agrupados na pinha que chega a pesar até $5 \mathrm{~kg}$. As sementes da araucária (pinhões) são ricas

FLORESTA, Curitiba, PR, v. 48, n. 2, p. 203-212, abr/jun. 2018.

Brito. P. C. et.al.

ISSN eletrônico 1982-4688

DOI: $10.5380 /$ rf.v48 i2.54930 
em reservas energéticas (57\% de amido) e em aminoácidos (IPEF, 2003). Em Santa Catarina as pinhas geralmente amadurecem entre abril a julho (ZECHINI et al., 2012).

Segundo a Resolução do CONAMA n. 278, de 24 de maio de 2001, não são permitidos o corte e a exploração da araucária em populações naturais, pois a espécie está inclusa na lista oficial do Instituto Brasileiro do Meio Ambiente e dos Recursos Naturais Renováveis (IBAMA) para espécies da flora brasileira ameaçadas de extinção, por causa da exploração desordenada e comercialização de sua madeira (MMA, 2001). Por essa razão, o pequeno produtor rural, devido à legislação restritiva, buscou uma alternativa de obter renda extra para a propriedade na comercialização de produtos não madeireiros (SILVA; REIS, 2009; FIGUEIREDO FILHO et al., 2010).

Desta forma, a coleta de pinhões se tornou uma atividade extremamente importante para as famílias que vivem em áreas de florestas naturais do planalto catarinense, representando uma das principais fontes de rendas anuais. Nesse processo, a mão de obra familiar é amplamente utilizada. A coleta é, normalmente, realizada há vários anos pelas famílias residentes no entorno dos remanescentes de florestas com araucária (SILVA; REIS, 2009). O procedimento de coleta do pinhão é, em geral, realizado conforme preconiza a Instrução Normativa $\mathrm{N}^{\circ} 20$ do IBAMA, ressaltando a necessidade do uso de equipamentos de proteção individual, como luvas, botas, capacetes e cintas de segurança.

O esforço e desgaste físico gerado pela atividade de coleta de sementes podem ser estudados por meio da carga de trabalho físico, que, segundo Couto (1995), corresponde à quantidade de carga máxima que um indivíduo pode suportar em determinadas condições, podendo ser obtida por meio da aplicação de métodos fisiológicos, como palpação das artérias ou aferição da frequência cardíaca. Couto (1995) destaca ainda que a capacidade física do ser humano para exercer atividades pesadas geralmente é muito baixa, devido ao aparecimento de sintomas de fadiga por sobrecarga física. Desta forma, a capacidade física de trabalho depende do esforço desenvolvido, da duração da atividade e das condições individuais, como saúde, nutrição e condicionamento decorrente da prática da atividade. À medida que a fadiga aumenta, reduz-se o ritmo de trabalho, atenção e rapidez de raciocínio, tornando o trabalhador menos produtivo e sujeito a erros e acidentes.

Neste sentido, para a aferição da frequência cardíaca dos trabalhadores durante o trabalho é comumente utilizado, na área florestal, o medidor cardíaco Polar Electro OY (LOPES et al., 2011; VOSNIAK et al., 2010; OLIVEIRA et al., 2014). O equipamento armazena, simultaneamente, a frequência cardíaca e o tempo de medição, permitindo assim que os dados sejam analisados para definição do esforço físico da atividade e para subsidiar na melhoria das condições de trabalho.

Outro ponto a se destacar é a postura adotada pelos trabalhadores na realização das atividades, pois, segundo Couto (1995), o trabalho realizado com posturas inadequadas pode acarretar graves implicações para a saúde. A postura é considerada mais perigosa quanto mais se afasta da posição de neutralidade funcional ou anatômica, ocasionando, assim, doenças ocupacionais e lesões. De acordo com Silva et al. (2007), se um trabalhador permanece com postura forçada durante um longo período de tempo, existe o risco iminente de uma sobrecarga física, o que gera quadros álgicos e desequilíbrios de força.

Lopes et al. (2011) dizem que a utilização prática dos resultados de análises posturais é útil na resolução de problemas de acidentes no trabalho ou quedas de produtividade. Posturas que oferecem risco ao trabalhador podem ser corrigidas por meio de treinamentos específicos objetivando a adoção de posturas mais seguras, saudáveis e confortáveis para a realização da atividade.

Diante disso, objetivou-se, nesta pesquisa, analisar a carga de trabalho físico e as posturas adotadas pelos trabalhadores na atividade de coleta do pinhão, visando à reorganização ergonômica do trabalho e a melhoria das condições de conforto, saúde e segurança dos trabalhadores.

\section{MATERIAL E MÉTODOS}

\section{Caracterização da área de estudo}

A pesquisa foi realizada no município de Painel, região Serrana do estado de Santa Catarina (Figura 1), localizado na latitude $27^{\circ} 55^{\prime} 44^{\prime \prime}$ Sul e longitude 50 06' $18^{\prime \prime}$ Oeste, em uma altitude de 1.144 m (PAINEL, 2010). Os dados foram coletados na atividade de coleta de pinhão em área de ocorrência natural da espécie no mês de maio de 2010 , com temperatura média de $13,5^{\circ} \mathrm{C} \pm 3,48^{\circ} \mathrm{C}$ durante a jornada de trabalho. As árvores de araucária situavam-se aleatoriamente nas propriedades rurais, possuindo uma altura média de $15 \mathrm{~m}$.

Foram avaliados cinco trabalhadores (que corresponde ao censo de uma equipe de trabalho), os quais apresentavam uma idade média de 28 anos e massa corporal média de $87 \mathrm{~kg}$, com experiência na função variando de quatro a quinze anos. 


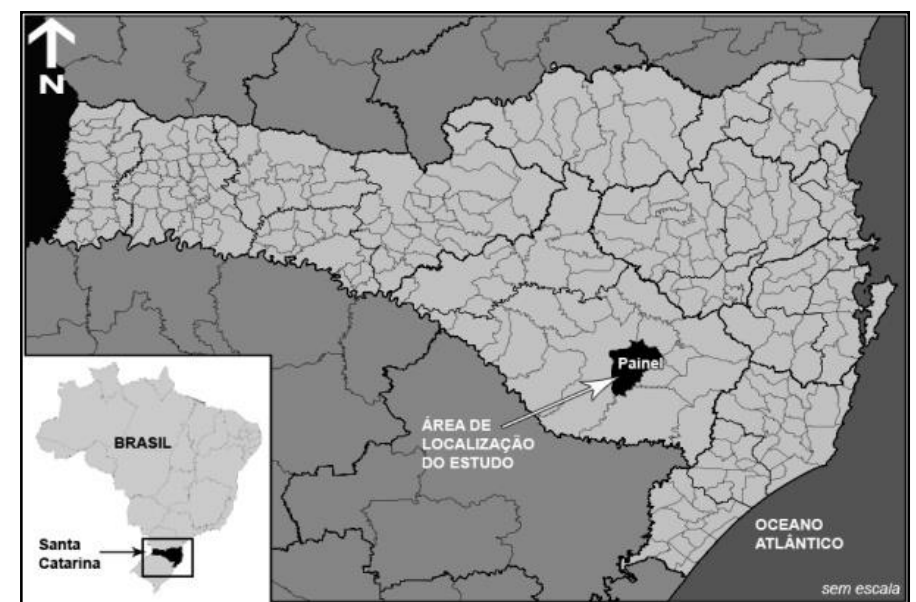

Figura 1. Área de localização do estudo.

Figure 1. Study location.

\section{Descrição da atividade}

A atividade de coleta do pinhão era realizada por pequenos proprietários rurais em áreas com remanescentes de floresta ombrófila mista em estágio secundário. Normalmente, é realizada manualmente por meio de quatro métodos: escalada das árvores com o auxílio de esporas; escalada por meio de entalhos feitos nas árvores; escalada com o auxílio de escada e derrubada das pinhas sem a necessidade de subida nas árvores. Nesta pesquisa foi estudada a escalada das árvores com uso de esporas, sendo o método predominante na região de estudo (Figura 2).

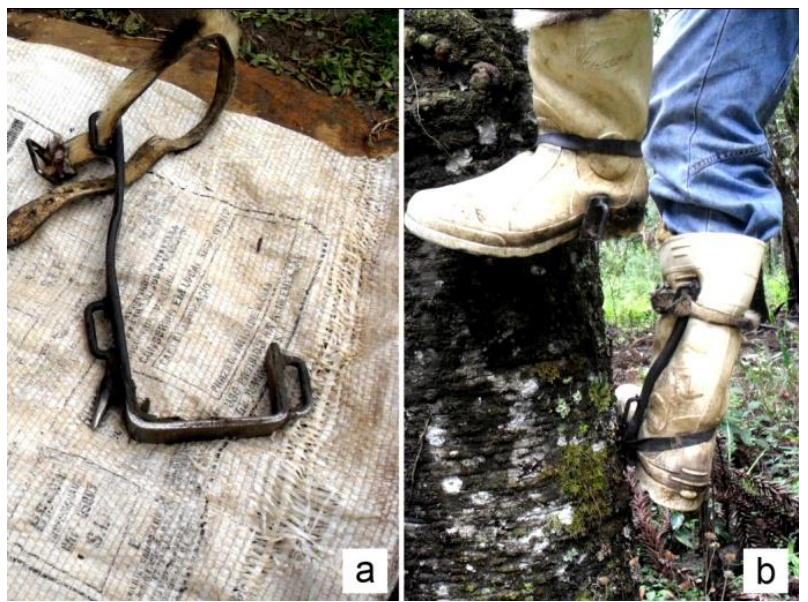

Figura 2. Ganchos utilizados no auxílio na escalada da árvore (a) e em uso no trabalho (b).

Figure 2. Hooks used to aid in tree climbing (a) and in use at work (b).

A atividade de coleta de pinhões era caracterizada pela escalada nas árvores e posterior derrubada das pinhas por meio de uma vara de bambu com aproximadamente $6 \mathrm{~m}$ de comprimento e massa de $5 \mathrm{~kg}$. Em seguida, os coletores desciam e efetuavam a catação das pinhas sobre o terreno para o posterior transporte até o local de armazenamento.

\section{Estudo de tempos e movimentos}

Para esta pesquisa, o estudo de tempos e movimentos foi realizado por meio da cronometragem de tempos contínuos, com auxílio de formulários específicos. Durante a realização do estudo, não existiu um padrão no tempo de coleta do pinhão, sendo que os coletores iniciavam e terminavam o trabalho de acordo com as condições climáticas do local. A jornada de trabalho média, durante a realização do estudo, foi de 3,3 horas.

O ciclo de trabalho da atividade de coleta de pinhão foi subdividido nas etapas de deslocamento, subida,

FLORESTA, Curitiba, PR, v. 48, n. 2, p. 203-212, abr/jun. 2018.

Brito. P. C. et.al.

ISSN eletrônico 1982-4688

DOI: $10.5380 /$ rf.v48 i2.54930 
derrubada de pinhas, descida, catação e interrupções, conforme descrito na Tabela 1 .

Tabela 1. Divisão e descrição das fases estudadas na coleta do pinhão.

Table 1. Division and description of the phases studied during the pinion collection.

\section{Fase do Ciclo de Trabalho \\ Descrição}

Deslocamento

Tempo despendido no deslocamento do trabalhador entre as árvores de araucária.

Subida

Tempo despendido pelo trabalhador na escalada de uma árvore.

Derrubada de Pinhas

Tempo despendido pelo trabalhador na derrubada das pinhas.

Descida

Tempo despendido pelo trabalhador na descida de uma árvore.

Catação

Tempo despendido pelo trabalhador na catação dos frutos e sementes caídos sobre o terreno.

Interrupções

Pausas pessoais durante a jornada de trabalho.

\section{Análise da carga de trabalho físico}

A carga de trabalho físico (CTF) foi avaliada por meio do levantamento da frequência cardíaca dos coletores, com o uso do monitor de frequência cardíaca Polar S610. O equipamento é composto de três partes: um receptor digital de pulso, um transmissor com eletrodos e uma correia elástica.

O receptor de pulso armazenava a frequência cardíaca (bpm) captada pelos eletrodos, que foram fixados na altura do tórax por meio de uma correia elástica. O monitor foi instalado no trabalhador no início da jornada de trabalho e retirado ao final, sendo a frequência captada e armazenada em intervalos de 5 segundos. De posse dos dados de frequência cardíaca obtidos, calculou-se a carga cardiovascular do trabalho de acordo com metodologia proposta por Apud (1989), que corresponde à porcentagem da frequência cardíaca durante o trabalho em relação à frequência cardíaca máxima utilizável, conforme a equação 1.

$$
\operatorname{CCV}(\%)=\frac{\text { FCT }-\mathrm{FCR}}{\mathrm{FCM}-\mathrm{FCR}} \times 100
$$

Em que: $\mathrm{CCV}=$ carga cardiovascular $(\%) ; \mathrm{FCT}=$ frequência cardíaca de trabalho $(\mathrm{bpm}) ; \mathrm{FCR}=$ frequência cardíaca no repouso (bpm); e FCM = frequência cardíaca máxima (220 - idade) (bpm).

Quando a CCV ultrapassou o limite recomendado de $40 \%$, foi calculada a frequência cardíaca limite (FCL) recomendada para uma jornada de trabalho de 8 horas, por meio da equação 2.

$$
\mathrm{FCL}=0,40 \times(\mathrm{FCM}-\mathrm{FCR})+\mathrm{FCR}
$$

Em seguida, calculou-se o tempo de repouso necessário para a atividade, conforme a expressão descrita abaixo.

$$
\mathrm{Tr}=\frac{\mathrm{Ht} \times(\mathrm{FCT}-\mathrm{FCL})}{\mathrm{FCT}-\mathrm{FCR}}
$$

Em que: $\mathrm{Tr}=$ tempo de descanso, repouso ou pausas (min); e $\mathrm{Ht}=$ duração do trabalho (min).

Com os resultados obtidos, foi possível determinar a CTF em cada fase da coleta de pinhão e estabelecer os limites aceitáveis para um desempenho contínuo no trabalho. Em seguida, foi determinada a duração da jornada de trabalho, a duração de cada fase da atividade e a frequência das pausas de acordo com a capacidade física dos trabalhadores. A classificação do trabalho foi realizada conforme Tabela 2. 
Tabela 2. Classificação da carga de trabalho físico de acordo com a frequência cardíaca.

Table 2. Classification of physical workload according to heart rate.

\begin{tabular}{lc}
\multicolumn{1}{c}{ Classificação do trabalho } & Frequência cardíaca média (bpm) \\
\hline Muito Leve & $<75$ \\
Leve & $75-99$ \\
Moderadamente Pesado & $100-124$ \\
Pesada & $125-149$ \\
Pesadíssima & $150-175$ \\
Extremamente Pesada & $>175$ \\
\hline Fonte: adaptado de lida (2016)
\end{tabular}

\section{Análise de postura}

A determinação das posturas típicas adotadas pelos coletores na execução do trabalho foi realizada por meio de registros fotográficos, filmagens e anotações de campo, permitindo a recomposição do ciclo de trabalho e definição das posturas típicas adotadas pelos trabalhadores na execução de cada etapa da coleta do pinhão. Para a análise das posturas foi utilizado o modelo OWAS por meio do software WinOWAS®, versão disponibilizada gratuitamente sob domínio WinOWAS Copyright@ 1996 pela Tampere University of Technology Occupational Safety Engineering (WINOWAS, 1990). Em seguida, obteve-se a frequência de permanência dos coletores nas diferentes posturas selecionadas.

De posse das imagens dos trabalhadores nas posturas típicas, foi selecionada a classe da posição dos membros superiores e inferiores, das costas e do peso da carga manuseada pelos trabalhadores em cada fase do trabalho (Tabela 3). Em seguida, foi gerada uma sequência de números, representando a análise do método OWAS e, ao final das análises, foram verificados os pontos críticos e classificadas as posturas típicas adotadas nas seguintes categorias de ações:

- Categoria 1: Postura normal, não sendo exigida nenhuma medida corretiva.

- Categoria 2: Postura a ser verificada na próxima revisão dos métodos de trabalho.

- Categoria 3: Postura prejudicial à saúde, devendo ser tomadas medidas corretivas para mudar a postura o mais breve possível.

- Categoria 4: Postura extremamente prejudicial à saúde, devendo ser tomadas medidas corretivas imediatamente

Tabela 3. Composição dos códigos do método OWAS conforme a postura adotada.

Table 3. Composition of the OWAS method codes according to the adopted posture.

\begin{tabular}{|c|c|c|c|}
\hline Costas & Braços & Pernas & Peso \\
\hline $\begin{array}{l}\text { (1) retas } \\
\text { (2) curvadas } \\
\text { (3) torcidas ou com } \\
\text { curso lateral em } \\
\text { curva. } \\
\text { (4) curvadas e } \\
\text { torcidas ou } \\
\text { curvadas para } \\
\text { frente e curso } \\
\text { lateral. }\end{array}$ & $\begin{array}{l}\text { (1) os dois abaixo do nível } \\
\text { dos ombros. } \\
\text { (2) somente um dos braços } \\
\text { erguido acima do nível } \\
\text { dos ombros. } \\
\text { (3) ambos os braços } \\
\text { erguidos acima do nível } \\
\text { dos ombros. }\end{array}$ & $\begin{array}{l}\text { (1) sentado, com as pernas abaixo } \\
\text { do nível das nádegas. } \\
\text { (2) em pé, com ambas as pernas } \\
\text { esticadas. } \\
\text { (3) em pé, com o peso em uma } \\
\text { perna e a outra perna esticada. } \\
\text { (4) em pé, ou agachado, com } \\
\text { ambos os joelhos flexionados. } \\
\text { (5) em pé, ou agachado com um } \\
\text { dos joelhos dobrados. } \\
\text { (6) ajoelhado com um ou ambos os } \\
\text { joelhos. } \\
\text { (7) andando ou se movimentando. }\end{array}$ & $\begin{array}{l}\text { (1) } P<10 \mathrm{kgf} \\
\text { (2) } 10 \leq P<20 \mathrm{kgf} \\
\text { (3) } P \geq 20 \mathrm{kgf}\end{array}$ \\
\hline
\end{tabular}

Fonte: Adaptado do manual do WinOWAS (1990). 


\section{RESULTADOS}

O resultado do ciclo operacional da atividade de coleta de pinhão encontra-se na Figura 3.

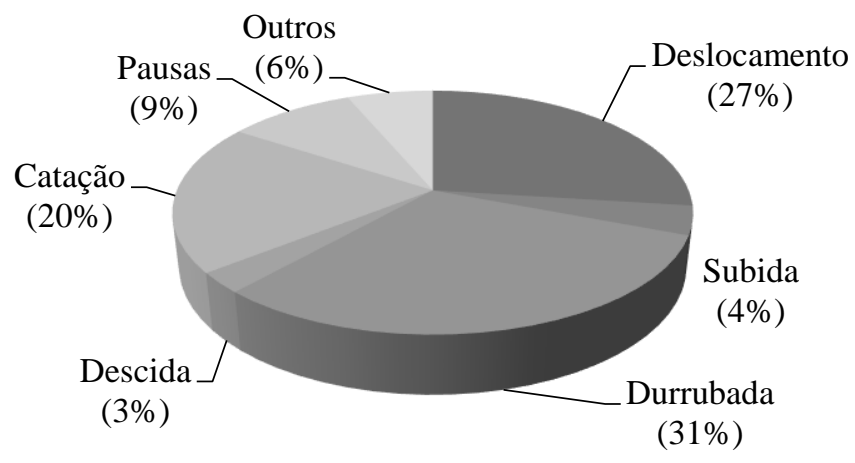

Figura 3. Percentual do tempo consumido na atividade de coleta de pinhão.

Figure 3. Percentage of time consumed in the pinion collection activity.

Como pode ser observado na Figura 3, as fases de derrubada das pinhas, deslocamento entre árvores e catação consumiram os maiores tempos do ciclo de trabalho, com 31, 27 e $20 \%$ do ciclo de trabalho, respectivamente. Enquanto isso, as fases de subida e descida foram as que apresentaram menor tempo de duração do ciclo de trabalho, representados por $4 \%$ e $3 \%$, respectivamente.

\section{Carga de trabalho físico}

$\mathrm{Na}$ Tabela 4, são apresentados os percentuais do tempo utilizado pelos trabalhadores em cada fase do trabalho; as frequências cardíacas média em repouso, no trabalho e a máxima utilizável; a carga cardiovascular; a frequência cardíaca limite; o tempo de repouso necessário e a classificação do trabalho.

Tabela 4. Carga de trabalho físico da atividade de coleta de pinhão.

Table 4. Physical work load of the pinion collection activity.

\begin{tabular}{|c|c|c|c|c|c|c|c|c|c|}
\hline $\begin{array}{c}\text { Fases do Ciclo } \\
\text { de Trabalho }\end{array}$ & $\begin{array}{c}\text { Tempo } \\
\text { Duração } \\
(\%)\end{array}$ & $\begin{array}{c}\text { FCT } \\
(\text { bpm) }\end{array}$ & $\begin{array}{c}\text { CCV } \\
(\%)\end{array}$ & $\begin{array}{c}\text { FCR } \\
(\text { bpm) }\end{array}$ & $\begin{array}{c}\text { FCM } \\
(\text { bpm) }\end{array}$ & $\begin{array}{c}\text { FC } \\
\text { pico } \\
(\text { bpm) }\end{array}$ & $\begin{array}{c}\text { FCL } \\
(\text { bpm) }\end{array}$ & $\underset{(\mathrm{min} / \mathrm{h})}{\mathbf{T R}}$ & Classificação \\
\hline Deslocamento & 27 & 107 & 28 & \multirow{6}{*}{74,4} & \multirow{6}{*}{192} & 151 & \multirow{6}{*}{121} & \multirow{6}{*}{2} & $\begin{array}{c}\text { Moderadamente } \\
\text { Pesado }\end{array}$ \\
\hline Subida & 4 & 140 & 56 & & & 167 & & & Pesada \\
\hline $\begin{array}{c}\text { Derrubada de } \\
\text { Pinhas }\end{array}$ & 31 & 121 & 40 & & & 163 & & & $\begin{array}{c}\text { Moderadamente } \\
\text { Pesado }\end{array}$ \\
\hline Descida & 3 & 123 & 42 & & & 153 & & & $\begin{array}{c}\text { Moderadamente } \\
\text { Pesado }\end{array}$ \\
\hline Catação & 20 & 110 & 30 & & & 150 & & & $\begin{array}{l}\text { Moderadamente } \\
\text { Pesado }\end{array}$ \\
\hline Pausas & 9 & 103 & 24 & & & 133 & & & $\begin{array}{c}\text { Moderadamente } \\
\text { Pesado }\end{array}$ \\
\hline Média & - & 117 & 37 & 74 & 192 & 153 & 121 & - & - \\
\hline
\end{tabular}

FCT: Frequência Cardíaca no Trabalho; CCV: Carga Cardiovascular; FCR: Frequência Cardíaca em Repouso; FCM: Frequência Cardíaca Máxima (220 - idade); FCL: Frequência Cardíaca Limite; TR: Tempo de Repouso.

Como pode-se observar na Tabela 4, as fases de deslocamento e pausas apresentaram as menores frequências cardíacas 107 e 103 bpm com cargas cardiovasculares de 28 e 24\%, respectivamente, acarretando, com isso, os menores riscos aos trabalhadores em relação à carga de trabalho físico.

As fases de subida, derrubada de pinhas e descida da árvore foram as fases de trabalho de maior exigência física, apresentando riscos para a saúde do trabalhador; além do maior risco de acidentes pela periculosidade do trabalho, estando os valores de CCV acima do limite de 40\% recomendado por Apud (1989). As demais fases do 
trabalho não tiveram o limite de carga cardiovascular ultrapassada, não sendo necessário o cálculo do tempo de repouso e sendo, portanto, de menor exigência física, podendo, assim, ser executadas normalmente, sem riscos para a saúde dos trabalhadores.

\section{Análise de postura}

A Tabela 5 apresenta as posturas típicas adotadas pelos trabalhadores em cada fase da coleta de pinhão com relação às costas, braços e pernas, carga suportada, código de classificação correspondente, classificação de acordo com as categorias conforme o programa OWAS e recomendação ergonômica.

Tabela 5. Classificação das posturas típicas adotadas pelos trabalhadores de acordo com o método OWAS.

Table 5. Classification of the typical postures adopted by workers according to the OWAS method.

\begin{tabular}{|c|c|c|c|c|}
\hline $\begin{array}{l}\text { Fases do } \\
\text { Trabalho } \\
\end{array}$ & Postura Típica & $\begin{array}{l}\text { Código } \\
\text { OWAS } \\
\end{array}$ & Classificação & Recomendações \\
\hline Subida & & 1221 & Categoria 1 & $\begin{array}{c}\text { Postura normal dispensa } \\
\text { cuidados, a não ser em casos } \\
\text { excepcionais. }\end{array}$ \\
\hline Derrubada & & 2131 & Categoria 2 & $\begin{array}{l}\text { Postura que deve ser } \\
\text { verificada na próxima } \\
\text { revisão dos métodos de } \\
\text { trabalho. }\end{array}$ \\
\hline Descida & & 1221 & Categoria 1 & $\begin{array}{c}\text { Postura normal dispensa } \\
\text { cuidados, a não ser em casos } \\
\text { excepcionais. }\end{array}$ \\
\hline Catação & & 2151 & Categoria 2 & $\begin{array}{l}\text { Postura que deve ser } \\
\text { verificada na próxima } \\
\text { revisão dos métodos de } \\
\text { trabalho. }\end{array}$ \\
\hline $\begin{array}{c}\text { Desloca- } \\
\text { mento }\end{array}$ & & 1161 & Categoria 1 & $\begin{array}{c}\text { Postura normal dispensa } \\
\text { cuidados, a não ser em casos } \\
\text { excepcionais. }\end{array}$ \\
\hline Pausas & & 1111 & Categoria 1 & $\begin{array}{c}\text { Postura normal dispensa } \\
\text { cuidados, a não ser em casos } \\
\text { excepcionais. }\end{array}$ \\
\hline
\end{tabular}

Nas fases de subida e descida da árvore, o coletor encontrava-se com as costas retas, um dos braços erguidos acima do nível dos ombros, com o peso do corpo em uma das pernas e a outra esticada, e sem transportar

FLORESTA, Curitiba, PR, v. 48, n. 2, p. 203-212, abr/jun. 2018.

Brito. P. C. et.al.

ISSN eletrônico 1982-4688

DOI: $10.5380 /$ rf.v48 i2.54930 
peso. Com isso, por meio da análise obtida pelo método OWAS, constatou-se que a postura adotada pelos coletores nessas fases dispensa cuidados especiais, sendo classificadas na categoria 1, ou seja, trata-se de uma postura normal que não exige nenhuma medida corretiva.

$\mathrm{Na}$ fase de derrubada de pinhas, o coletor permanecia com as costas curvadas, os dois braços abaixo do nível dos ombros, em pé ou agachado, porém com ambos os joelhos flexionados para equilibrar-se na copa das árvores, e carregando um peso menor que $10 \mathrm{kgf}$ (massa de $6 \mathrm{~kg}$ ). Nessa situação, a postura adotada pelo coletor foi enquadrada na categoria 2 , apresentando riscos à saúde e necessitando de uma revisão do método de trabalho. A fase de catação foi também classificada na categoria 2, necessitando de uma revisão dos métodos de trabalho, pois os coletores permaneciam com as costas inclinadas, os dois braços abaixo do nível do ombro e com uma das pernas ajoelhadas ou com ambas flexionadas, situação considerada desfavorável e podendo causar riscos à saúde.

Por fim, as fases de deslocamento e pausas foram classificadas na categoria 1, pois o coletor encontravase com as costas eretas, os dois braços abaixo do nível do ombro e com ambas as pernas esticadas, estando a postura adotada adequada e não sendo necessária a adoção de medidas ergonômicas.

\section{DISCUSSÃO}

A fase de derrubada das pinhas está diretamente relacionada com o número de pinhas existente em cada árvore (média de 26). O elevado tempo gasto para realização dessa atividade ocorreu pela maior dificuldade do trabalhador em se manter apoiado na árvore e no deslocamento entre os galhos para realização da coleta dos frutos com a vara de bambu. Além disso, é importante ressaltar que, devido ao elevado risco de acidentes desta fase do trabalho, o coletor procurava exercer a coleta do pinhão com grande atenção, contribuindo para o elevado tempo em relação às demais fases do trabalho.

O elevado tempo de deslocamento ocorreu pois havia árvores de araucária que se encontravam esparsas na propriedade pelo diferente tempo de maturação e por trata-se de uma espécie natural que apresentava uma distribuição aleatória. Já a fase de catação apresentou um alto tempo, pois algumas pinhas, quando caíam sobre o terreno, se rompiam espalhando as sementes (pinhões) em meio aos resíduos de galhos e folhas presentes no local, dificultando, assim, a posterior catação das pinhas. Entretanto, é importante ressaltar que esta fase não é muito comum entre todos coletores de pinhão, pois, em alguns casos, existe a presença de um ajudante que realiza a catação das pinhas durante a derrubada, otimizando o trabalho.

É importante ainda ressaltar que, apesar do menor tempo de duração do ciclo de trabalho, as fases de subida e descida das árvores, mesmo sendo realizadas com uso de equipamentos auxiliares, são de elevado risco de acidentes. Métodos alternativos para a maior segurança dos trabalhadores envolvidos nesta atividade devem ser estudados, principalmente nas pequenas e médias propriedades rurais.

Quanto à carga cardiovascular, as fases de subida, derrubada de pinhas e descida da árvore foram as fases do trabalho de maior exigência física apresentando riscos para a saúde do trabalhador, além do maior risco de acidentes pela periculosidade do trabalho, estando os valores de CCV acima do limite de $40 \%$ recomendado por Apud (1989). Por isso, com uma CCV de 56\% para a fase de subida da árvore, o tempo de repouso necessário foi de 15 minutos por hora de trabalho, situação que ocorria caso o coletor realizasse somente esta fase. Entretanto, é importante ressaltar que, na prática, este tempo será reduzido pelo fato dos coletores desenvolverem outras fases de menor exigência física durante o trabalho, causando uma compensação no do esforço físico.

$\mathrm{Na}$ análise postural, após verificar que os trabalhadores adotaram posturas inadequadas nas fases de derrubada e catação das pinhas, verificou-se, também, que é necessária a adoção de medidas ergonômicas para a melhoria das posturas adotadas. Esse resultado foi semelhante ao trabalho realizado por Nogueira e Fiedler (2017), que ao analisarem as posturas adotadas em atividades extrativistas de Açaí pelo método OWAS, verificaram que as posturas adotadas podem causar danos e afetar a saúde do trabalhador, apresentando a necessidade de medidas ergonômicas, como rodízio entre os trabalhadores, bem como a adoção de pausas durante a jornada de trabalho.

É importante ressaltar que as fases de derrubada e catação das pinhas podem não ter apresentado riscos imediatos à saúde, porém tratam-se de fases do trabalho em que os trabalhadores permaneciam por longos períodos de tempo nessas posições, com $31 \%$ e $20 \%$ do tempo total da atividade, respectivamente. Couto (1995) afirma que a permanência por longos períodos de temo em posturas inadequadas pode causar doenças ocupacionais e lesões.

Como a coleta do pinhão é uma atividade típica das propriedades rurais da região Sul do Brasil, ela é realizada e controlada pelo próprio trabalhador, não havendo uma orientação prévia dos trabalhadores em relação à adoção de posturas corretas no trabalho. Por isso, ficou evidente a necessidade de novos estudos e de recomendações aos trabalhadores, por meio de agências extensionistas, de cursos e treinamentos de conscientização dos trabalhadores em relação à adoção de posturas corretas no trabalho, do uso de equipamentos 
de proteção, bem como através do desenvolvimento de novos métodos de trabalho que contribuíram para a melhoria das condições de conforto, saúde e segurança dos trabalhadores rurais.

\section{CONCLUSÕES}

- A subida e descida das árvores foram as fases do ciclo de trabalho de maior exigência física e com elevado risco de acidentes;

- Os deslocamentos entre árvores consumiram um elevado tempo da jornada de trabalho, afetando o tempo de execução da atividade, porém contribuiu como forma de compensação para a redução do esforço físico;

- A atividade de coleta do pinhão foi classificada de modo geral como moderadamente pesada, necessitando de adoção de medidas ergonômicas para a melhoria das condições de saúde e segurança dos trabalhadores;

- Os trabalhadores adotaram posturas inadequadas nas fases de derrubada e catação das pinhas, sendo necessária a adoção de medidas ergonômicas para a melhoria das posturas adotadas.

\section{REFERÊNCIAS}

APUD, E. Guidelines on ergonomics study in forestry. Genebra: ILO, 1989.

BRASIL. Lei $n^{\circ} 11.428$, de 22 de dezembro de 2006. Bioma Mata Atlântica. Diário Oficial da República Federativa do Brasil, Brasília, DF, 26 dez., 2006.

COUTO, H. A. Ergonomia aplicada ao trabalho: o manual técnico da máquina humana. Belo Horizonte. Ergo Editora, v.1 e 2, 1995.

FIEDLER, N. C.; FERREIRA, A. H. S.; VENTUROLI, F.; MINETTE, L. J. Avaliação da carga de trabalho físico exigida em operações de produção de mudas ornamentais no Distrito Federal - um estudo de caso. Árvore, Viçosa, v. 31, n. 4, p. 703-708, mar. 2007.

FIGUEIREDO FILHO, A.; ORELlANA, E.; NASCIMENTO, F.; DIAS, A.N.; INOUE, M. T. Produção de sementes de Araucaria angustifolia em plantio e em floresta natural no centro-sul do estado do Paraná. Floresta, Curitiba, v. 41, n. 1, p. 155-162, 2011.

IIDA, I. Ergonomia; projeto e produção. 3 ed. São Paulo: Edgard Blucher, 2016. 850 p.

INSTITUTO DE PESQUISAS E ESTUDOS FLORESTAIS - IPEF. Identificação de espécies florestais: $\begin{array}{llll}\text { Araucaria angustifólia } 2003 . & \text { Disponível }\end{array}$ <http://www.ipef.br/identificacao/araucaria.angustifolia.asp>. Acesso em: 20. Abr. 2009.

LOPES, E. S.; OLIVEIRA, F. M.; RODRIGUES, C. K. Determinação da carga física de trabalho na atividade de aplicação manual de herbicida. Ambiência, Guarapuava, v. 7, n. 2, p. 329-337, 2011.

LORENZI, H. Árvores brasileiras: manual de identificação e cultivo de plantas arbóreas do Brasil. v. 1. São Paulo: Nova Odessa, 5. ed. 2008. 384 p.

MMA - Ministério do Meio Ambiente. Resolução Conama n 278, de 24 de maio de 2001. Dispõe contra corte e exploração de espécies ameaçadas de extinção da flora da Mata Atlântica. Diário Oficial da União, 138-E, 18 de julho de 2001, Seção 1, p. $\quad 51-52$. Disponível em: < http://www.mma.gov.br/port/conama/legiabre.cfm?codlegi=276>. Acesso em: 17 Out. 2017.

NASCIMENTO, T. P.; FIEDLER, N. C. Análise de posturas pelo método de OWAS em atividade extrativista do Açaí. Agropecuária Científica no Semiárido, Campina Grande. v. 13, n. 3, p. 236-240, 2017.

OLIVEIRA, F. M.; LOPES, E. S.; RODRIGUES, C. K. Avaliação da carga de trabalho físico e biomecânica de trabalhadores na roçada manual e semimecanizada. Cerne, Lavras, v. 20, n. 3, p. 419-425, 2014.

PAINEL, D. P. Safra do pinhão de 2010 será maior que a do ano passado. Correio Lageano. Jornal. 16/04/2010. Disponível em: <http://correiolageano.com.br/htmNoticia.php?id=27044\&c=2>

SILVA, C. V.; REIS, M. S. Produção de pinhão na região de Caçador, SC: aspectos da obtenção e sua importância para comunidades locais. Ciência Florestal, Santa Maria, v. 19, n. 4, p. 363-374, 2009.

FLORESTA, Curitiba, PR, v. 48, n. 2, p. 203-212, abr/jun. 2018.

Brito. P. C. et.al.

ISSN eletrônico 1982-4688

DOI: $10.5380 /$ rf.v48 i 2.54930 
SILVA, E. P.; MINETTE, L. J.; SOUZA, A. P. Análise ergonômica do trabalho de coveamento semimecanizado para o plantio de eucalipto. Scientia Forestalis, Piracicaba, n. 76, p 77-83, dez. 2007.

VOSNIAK, J.; LOPES E. S.; FIEDLER, N. C.; ALVES, R. T.; VENÂNCIO, D. L. Carga de trabalho físico e postura na atividade de coveamento semimecanizado em plantios florestais. Scientia Forestalis, Piracicaba v. 38, n. 88 , p. 589-598, 2010.

WIN-OWAS. Manual software for OWAS analysis. Tampere University of Technology, Occupational and $\begin{array}{llll}\text { Safety } \quad \text { Engineering (1996). } & \text { Disponível }\end{array}$ <home.spin.net.au/safehands/reference\%20documents/software\%20for\%20owas\%20analysis.pdf>.

ZECHINI, A. A.; SCHUSSLER, G.; SILVA, J. Z.; MATTOS, A. G.; PERONI, N.; MANTOVANI, A.; REIS, M. S. Produção, comercialização e identificação de variedades de pinhão no entorno da Floresta Nacional de Três Barras - SC. 2012. In: Biodiversidade Brasileira. v. 2, n. 1, p. 74-82, 2012. 